\title{
Decomposers and root feeders interactively affect plant defence in Sinapis alba
}

\author{
Maité Lohmann · Stefan Scheu • Caroline Müller
}

Received: 28 August 2008 / Accepted: 7 February 2009 / Published online: 1 March 2009

(C) Springer-Verlag 2009

\begin{abstract}
Aboveground herbivory is well known to change plant growth and defence. In contrast, effects of soil organisms, acting alone or in concert, on allocation patterns are less well understood. We investigated separate and combined effects of the endogeic earthworm species Aporrectodea caliginosa and the root feeding nematode species Pratylenchus penetrans and Meloidogyne incognita on plant responses including growth and defence metabolite concentrations in leaves of white mustard, Sinapis alba. Soil biota had a strong impact on plant traits, with the intensity varying due to species combinations. Nematode infestation reduced shoot biomass and nitrogen concentration but only in the absence of earthworms. Earthworms likely counteracted the negative effects of nematodes. Infestation with the migratory lesion-nematode $P$. penetrans combined with earthworms led to increased root length. Earthworm biomass increased in the presence of this species, indicating that these nematodes increased the food resources of earthworms-presumably dead and decaying roots.
\end{abstract}

Communicated by Julia Koricheva.

M. Lohmann · S. Scheu

Institute of Zoology, Darmstadt University of Technology,

Schnittspahnstraße 3, 64287 Darmstadt, Germany

Present Address:

S. Scheu

J.F. Blumenbach Institute of Zoology and Anthropology,

University of Göttingen, Berliner Str. 28,

37073 Göttingen, Germany

C. Müller ( $\square)$

Department of Chemical Ecology,

University of Bielefeld, Universitätsstraße 25,

33615 Bielefeld, Germany

e-mail: caroline.mueller@uni-bielefeld.de
Nitrogen-based defence compounds, i.e. glucosinolates, did not correlate with nitrogen levels. In the presence of earthworms, concentrations of aromatic glucosinolates in leaves were significantly increased. In contrast, infection with $P$. penetrans strongly decreased concentrations of glucosinolates (up to $81 \%$ ). Infestation with the sedentary nematode $M$. incognita induced aromatic glucosinolates by more than $50 \%$ but only when earthworms were also present. Myrosinase activities, glucosinolate-hydrolysing enzymes, were unaffected by nematodes but reduced in the presence of earthworms. Our results document that root-feeding nematodes elicit systemic plant responses in defence metabolites, with the responses varying drastically with nematode species of different functional groups. Furthermore, systemic plant responses are also altered by decomposer animals, such as earthworms, challenging the assumption that induction of plant responses including defence traits is restricted to herbivores. Soil animals even interact and modulate the individual effects on plant growth and plant defence, thereby likely also influencing shoot herbivore attack.

Keywords Multitrophic interactions - Brassicaceae · Glucosinolate $\cdot$ Myrosinase $\cdot$ Induction

\section{Introduction}

The phenotype of a plant is influenced by a number of factors that can act either on their own or in concert. Efficient resource capture, utilisation and allocation into growth, maintenance, storage or defence are essential functional traits, which determine the growth and fitness of plants and are prone to trade-offs (Matyssek et al. 2005). Plant secondary metabolites often increase in concentration due to herbivory or pathogen attack, and this can be measured in both 
local and systemic tissue (Karban and Baldwin 1997; Bezemer and van Dam 2005). Such induced defence is thought to be cost efficient and therefore evolutionary beneficial for the plant, since resources are allocated into the production of defence compounds only in the case of damage (Cipollini et al. 2003; Zangerl 2003). Induced responses of plants, including changes in expression of defensive traits, have been studied intensively in the context of insect herbivory on aerial parts of plants (Bartlet et al. 1999; Pontoppidan et al. 2005; Martin and Müller 2007). In contrast, the role of belowground animal-plant interactions for the induction of plant responses in aboveground tissue has attracted only little attention (but see van der Putten et al. 2001; Bezemer and van Dam 2005). This is surprising since roots are attacked by a variety of species, which can induce local or systemic plant responses including defence traits (Bezemer et al. 2003; Wurst et al. 2004; Bezemer and van Dam 2005). In addition to herbivores, recent evidence suggests that the production of plant secondary metabolites may also be modified by decomposer invertebrates (Wurst et al. 2004, 2006), adding to the complexity of factors affecting the allocation of plant resources to herbivore defence.

Soil animals affect plant physiology and chemistry by a number of mechanisms. They fundamentally alter plant performance by changing plant nutrition and thereby likely affect the nutritional value of plants for herbivores. Decomposers recycle plant material, stimulate microbial mineralisation processes and increase the accessibility of nutrients for plants (Scheu et al. 2005). Indeed, in the presence of decomposer invertebrates the growth of shoots and roots, as well as the concentration of nitrogen in shoots, can be increased (Wurst and Jones 2003; Wurst et al. 2006), with the consequence that plants in turn may become more attractive to herbivores (Scheu et al. 1999; Poveda et al. 2005). Phytophagous nematodes, on the other hand, are exceptional pathogens of numerous plant species and cause dramatic changes in morphology and physiology by reducing the water and nutrient uptake of their hosts (Lambert and Bekal 2002). These changes in the nutritional status of the plant may also impact plant defence levels due to changes in resource distribution and allocation.

Rhizosphere animals interact not only with plants but are imbedded in a complex food web, and food web interactions likely modify the effects of individual taxa on plant performance. For example, root herbivores may be controlled by predators, as documented for root-feeding moth larvae being killed by entomopathogenic nematodes (Preisser and Strong 2004). Root herbivores, however, may be killed not only by predators but also by "decomposers". In fact, one of the most prominent root herbivores, root-feeding (and other) nematodes, have been shown to be effectively digested by earthworms (Yeates 1981; Ilieva-Makulec and
Makulek 2002; Waghorn et al. 2002). Further, the effects of root herbivores on plant performance may also be modulated indirectly, e.g. by a decomposer-mediated increase in nutrient availability (Blouin et al. 2005).

Brassicaceae have been used as model plant family to study the effects on induction of plant responses including defence traits, as they are characterised by the presence of a rather specific inducible defence system (Wurst et al. 2006; Martin and Müller 2007). Species of this family contain glucosinolates, which consist of a thioglucoside moiety linked to a variety of amino acid-derived side chains (Halkier and Gershenzon 2006). Separated from the substrate, the enzyme myrosinase, a $\beta$-thioglucosidase, is stored in idioblasts. Upon tissue disruption, myrosinases catalyse the formation of glucosinolates into various hydrolysis products, including isothiocyanates, nitriles- and epithionitriles. These compounds are involved in efficient defence by decreasing the performance of herbivores and pathogens to the benefit of the plant (Wittstock et al. 2003). In contrast, glucosinolates and their hydrolysis products attract specialists able to circumvent the glucosinolate-myrosinase system ( $\mathrm{Li}$ et al. 2000; Müller and Wittstock 2005). For example, glucosinolates and myrosinase activities were shown to increase in Sinapis alba L. due to herbivory of specialist sawflies and mechanical damage, whereas generalist feeding induced glucosinolate concentrations only without affecting enzyme activities (Travers-Martin and Müller 2007). However, no long-term effects on plant growth were visible between herbivore-treated and control plants (Travers-Martin and Müller 2008). The effects of soil organisms on Brassicaceae have been studied only with regard to induction of glucosinolates, nothing is known of changes in myrosinase activities. Generally, information on the effects of decomposer-pathogen interactions on plant defence is lacking.

We investigated the influence of decomposers and plant pathogens acting either alone or in concert on the defence and development of white mustard, Sinapis alba. Decomposers were represented by the endogeic earthworm species Aporrectodea caliginosa (Savigny), and plant pathogens by two parasitic plant nematodes, Meloidogyne incognita (Kofoid \& White) and Pratylenchus penetrans (Cobb). Although there is some evidence that earthworms may also feed on roots (Baylis et al. 1986), recent evidence suggests that endogeic species in fact live on old carbon in soil and function as decomposers (Albers et al. 2006; Hyodo et al. 2008). By using two functionally different nematode species, we investigated if $M$. incognita, a sedentary root-knot nematode, influences plant development differently to $P$. penetrans, a migratory lesion-nematode. In contrast to the former, the latter species causes extensive root damage and thereby may provide additional food for decomposers. Earthworms were included to investigate whether they 
counteract the detrimental effects on plant growth by digesting nematodes and/or by improving plant nutrition. We expected that earthworms would, in particular, reduce the negative effects of the migratory nematode $P$. penetrans as additional nutrients provided by the nematodes to the earthworms, and thus to the plants, may allow the latter to compensate for root damage. Furthermore, we intended to prove if next-to-belowground herbivores, including decomposers such as earthworms, induce the production of putative plant defence compounds in aboveground plant compartments due to changes in plant nutritional levels, thereby changing the disposition of plants for being attacked by aboveground herbivores.

\section{Materials and methods}

\section{Experimental set-up}

Experimental containers (microcosms) consisted of PVC tubes $(25 \mathrm{~cm}$ height, $10 \mathrm{~cm}$ diameter) closed at the bottom by lids. The microcosms were equipped with ceramic cup lysimeters to allow drainage. A pump maintained a vacuum of -200 to $-500 \mathrm{hPa}$ to drain the soil via a hose system. A total of 60 microcosms were set up in a greenhouse $(16 \mathrm{~h}$ light, $20^{\circ} \mathrm{C}, 70 \%$ relative humidity). The microcosms were filled with $1,500 \mathrm{~g}$ soil (fresh weight). The soil $(0.074 \%$ nitrogen; $0.7 \%$ carbon; $\mathrm{C} / \mathrm{N}$ ratio 9.5 ) was taken from an arable field close to Darmstadt (Germany); it was sieved through a $1 \mathrm{~cm}$ mesh for homogenisation and to exclude animals and larger plant residues. The soil was defaunated by freezing at $-60^{\circ} \mathrm{C}$ for $24 \mathrm{~h}$, thawing for $24 \mathrm{~h}$ at room temperature, followed again by $24 \mathrm{~h}$ freezing at $-60^{\circ} \mathrm{C}$. Deep freezing effectively kills most soil invertebrates with minimum damage to microorganisms (Bruckner et al. 1995).

Seeds of S. alba var. Silenda (Kiepenkerl, Norken, Germany) were sown in seedling trays containing unfertilised soil (potting medium) and placed in the greenhouse ( $16 \mathrm{~h}$ light, $20^{\circ} \mathrm{C}, 70 \%$ relative humidity). Eight days later seedlings with 1-2 true leaves (next to the cotyledons) were transferred to individual microcosms. Microcosms were redistributed randomly within the greenhouse twice a week and watered with $25 \mathrm{ml}$ distilled water daily.

The experiment was set up in a two factorial design. Factors were nematodes [without $(-\mathrm{N})$, with migratory species $(+\mathrm{Nm})$, with sedentary species $(+\mathrm{Ns})]$ and earthworms [without $(-\mathrm{E})$ and with $(+\mathrm{E})$ ]. Ten replicates were set up per treatment. On day 9 of the experiment (plants with about 1-2 true leaves), two individuals of the endogeic earthworm species Aporrectodea caliginosa $(1.1 \pm 0.03 \mathrm{~g}$ fresh weight, full guts) were placed in half of the microcosms. The earthworms had been sampled on an arable field near Jena (Thüringen, Germany) and kept in a climate chamber at $5^{\circ} \mathrm{C}$ in defaunated soil for at least 1 week before the start of the experiment. The nematodes, Pratylenchus penetrans (provided by HZPC Holland BV, The Netherlands) and Meloidogyne incognita (provided by the BBA, Institute for Nematology and Vertebrate Research, Münster, Germany) were cultured on root tissue of Solanum lycopersicum. On day 15 of the experiment, when plants had developed about four leaves and a substantial root mass, $6 \mathrm{ml}$ of a suspension with approximately 7,800 juveniles of $P$. penetrans $(\mathrm{Nm})$ was added to the respective treatments; the next day 9,000 juveniles of $M$. incognita (Ns) were added. Time constraints did not allow adding of both nematode species on the same day.

Sampling and analyses

In order to be able to measure effects of nematodes with and without earthworms on plant performance, interactions were allowed to become established for over 2 weeks. On day 31 of the experiment, if possible, the oldest and the fourth youngest leaf (otherwise the next older or younger leaf) of each plant was harvested. The leaves were cut longitudinally, weighed, frozen in liquid nitrogen and stored at $-60^{\circ} \mathrm{C}$ for later analyses. This allowed both glucosinolate and myrosinase levels from the same leaf to be analysed (see below). Plant height was then measured and the plants cut at ground level, weighed and dried for $48 \mathrm{~h}$ at $50^{\circ} \mathrm{C}$. Roots were separated from soil by washing and, while washing, earthworms were collected, counted and weighed. Roots were weighed, one half preserved in $4 \%$ formalin and the other dried for $48 \mathrm{~h}$ at $50^{\circ} \mathrm{C}$.

Small preserved root samples were stained with acid fuchsine and examined for nematode infection using a dissecting microscope (three replicates only). Root length was measured using WinRHIZO (version 2004c, Regent Instruments, Québec, Canada). Dried roots and shoots were ground to a powder and approximately $2 \mathrm{mg}$ was weighed into tin capsules. Nitrogen and carbon content was measured by an elemental analyser (Carlo Erba EA 1108, Milan, Italy). Acetanilide $\left(\mathrm{C}_{8} \mathrm{H}_{9} \mathrm{NO}\right.$, Merck, Darmstadt, Germany) served as an internal standard.

Analysis of glucosinolates

The frozen samples of young and old leaves were freezedried, weighed and ground to a powder in a mill (Type MM301; Retsch, Haan, Germany). Glucosinolates were extracted in $80 \%$ methanol as described in detail in Martin and Müller (2007), adding allyl glucosinolate (Merck, Darmstadt, Germany) as internal standard. Briefly, glucosinolates were converted to desulfoglucosinolates and analysed by HPLC analysis on a 1100 Series chromatograph 
(Hewlett-Packard, Waldbronn, Germany). Elution was accomplished on a Supelco C-18 column (Supelcosil LC$18,250 \times 4.6 \mathrm{~mm}, 5 \mu \mathrm{m}$, Supelco, Bellefonte, PA) with a gradient (solvent A, water; solvent B, methanol) of $0-5 \%$ B (10 min), 5-38\% B (24 min), followed by a cleaning cycle. Peaks were quantified by the peak area at $229 \mathrm{~nm}$ (bandwidth $4 \mathrm{~nm}$ ) relative to the area of the internal standard peak, applying the response factors used by Martin and Müller (2007). Desulfoglucosinolates were identified by comparison of retention times and UV spectra with those of purified standards.

\section{Analysis of myrosinase activity}

Myrosinase extraction followed a protocol described previously (Müller and Sieling 2006; Travers-Martin et al. 2008). Frozen samples of young leaves were ground to a powder in a mill, extracted three times in $500 \mu \mathrm{l}$ extraction buffer (200 mM Tris, $10 \mathrm{mM}$ EDTA, pH 5.5) on ice, and centrifuged at $10,000 \mathrm{~g}$ for $10 \mathrm{~min}$ at $4^{\circ} \mathrm{C}$. Internal glucosinolates were eliminated from supernatants by use of $400 \mu$ Sephadex A-25-columns (0.1 g DEAE Sephadex A25 welled in $2 \mathrm{ml} 0.5 \mathrm{M}$ acetic acid buffer, pH 5; Sigma Aldrich, St. Louis, MO). Dry pellets were dissolved in the corresponding filtered extract solution. For determination of the combined activity of soluble and insoluble myrosinases, $150 \mu \mathrm{l}$ of each suspension was added to four individual cells on a 96-cell microplate. In two cells, $25 \mu 11.9 \mathrm{mM}$ p-OH-benzyl-glucosinolate/phosphate buffer was added as substrate, in the other two cells, $25 \mu$ phosphate buffer was added as background control. Released glucose was measured by addition of $50 \mu \mathrm{l}$ freshly mixed colour reagent, including glucose oxidase, peroxidase, 4-aminoantipyrine, and phenol. Glucose release was determined by measuring the absorbance at $490 \mathrm{~nm}$ on a Multiskan EX (Thermo Labsystems, Vantaa, Finland) for $90 \mathrm{~min}$ (one measurement every 2 nd minute, shaking mode between measurements) at room temperature $\left(22-24^{\circ} \mathrm{C}\right)$. Means of the two replicate measurements were calculated after subtraction of the mean of the background control. A glucose standard curve was included in each assay. The resulting enzyme kinetics were analysed for a linear range of enzyme activity and a timeframe of at least ten time points was used to determine enzyme activity.

\section{Statistical analysis}

Data were analysed by two factor analysis of variance (ANOVA) or, if necessary due to missing values, by general linear models (GLM). Factors were nematodes (three levels) and earthworms (two levels; see above). Some earthworms died or escaped during the experiment; microcosms of earthworm treatments in which none or only one of the two specimens survived until the end of the experiment were excluded from the analysis. Differences between means were analysed using Tukey's honestly significance difference tests (HSD) at $P<0.05$. Before analysing individual glucosinolates, the full complement of glucosinolates was analysed by repeated measures ANOVA (rmANOVA). If necessary, data were $\log (x+1)$ transformed to improve homogeneity of variances.

\section{Results}

\section{Earthworms}

Overall, $67 \%$ of the earthworms survived until the end of the experiment. The biomass of the surviving earthworms (with full guts) was generally increased, but the increase was more pronounced in the presence of nematodes $\left(F_{[2,19]}=4.72, P=0.02\right)$, and the effect varied between nematode species. In the presence of $P$. penetrans, earthworm biomass increased on average by $39 \%$, whereas in the presence of $M$. incognita and in the absence of nematodes it increased by only 29 and $30 \%$, respectively.

\section{Nematodes}

Nematodes successfully established in the microcosms and infested the plants. Infestation with $P$. penetrans $(817 \pm 302$ ind./g root fresh weight, mean \pm SD) was stronger than that with $M$. incognita $(214 \pm 80$ ind./g root fresh weight); infestation in the treatments with earthworms were similar to those without $(883 \pm 540$ and $342 \pm$ 58 ind./g root fresh weight, for P. penetrans and $M$. incognita, respectively).

\section{Plant biomass}

Shoot length was affected neither by earthworms $\left(F_{[1,54]}=0.19, P=0.66\right)$ nor by nematode infestation $\left(F_{[2,54]}=2.00, P=0.14\right)$. Furthermore, total plant biomass $\left(F_{[1,54]}=0.19, \quad P=0.66\right), \quad$ root biomass $\left(F_{[1,54]}<0.01\right.$, $P=0.98)$ and shoot biomass $\left(F_{[1,54]}=0.60, P=0.44\right.$, Fig. 1a) were not affected by earthworms. However, nematode infestation significantly reduced shoot biomass but only in the absence of earthworms (on average $-38 \%$; $F_{[2,54]}=3.53, \quad P=0.036$ for the nematode $\times$ earthworm interaction; Fig. 1a). In the presence of nematodes and earthworms, root biomass was slightly, but not significantly, increased $\left(F_{[2,54]}=1.59 ; P=0.21\right)$. Thus, total plant biomass remained unaffected $\left(F_{[2,54]}=0.42, P=0.66\right)$. In contrast, in the presence of earthworms, nematode infestation did not affect plant biomass, suggesting that earthworms counteracted the negative effect of nematodes. 

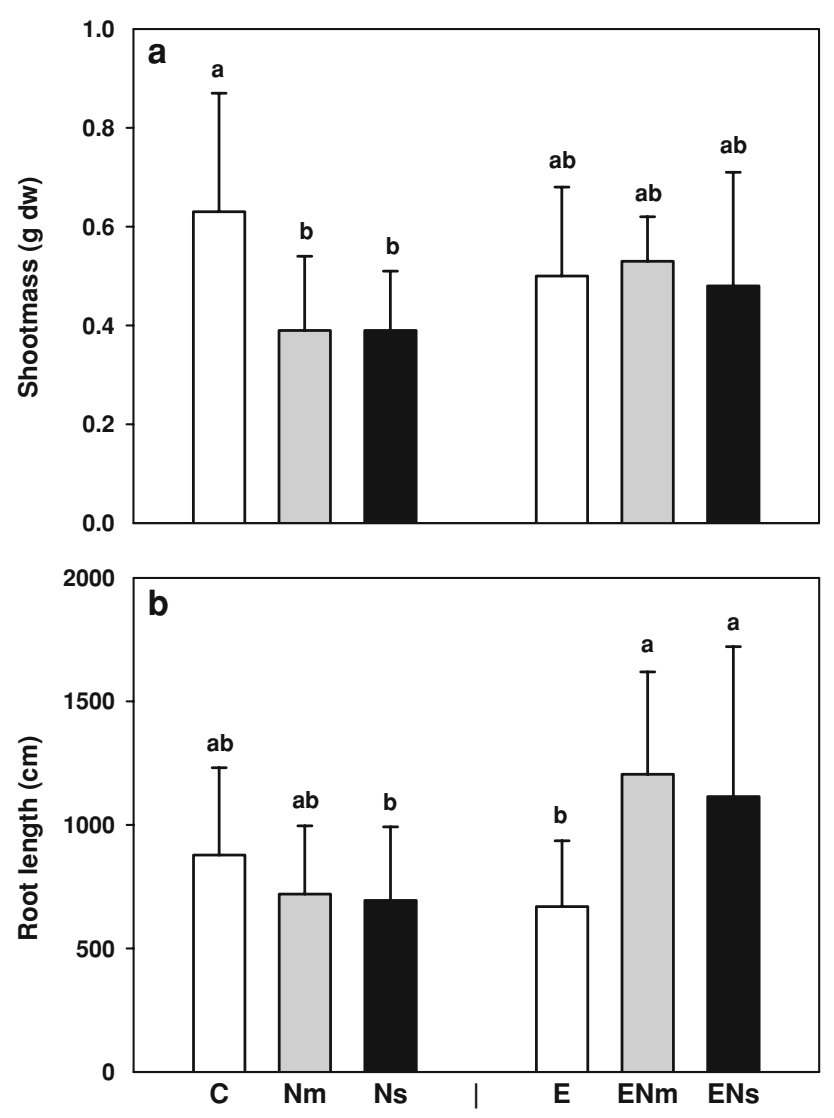

Fig. 1 Effects of earthworms (Aporrectodea caliginosa; E) and nematode infestation [Pratylenchus penetrans $(\mathrm{Nm})$ and Meloidogyne incognita $(N s)$ ] on (a) shoot biomass and (b) root length of Sinapis al$b a$. Significant differences are marked with different letters, $P<0.05$; Tukey's honestly significant difference (HSD), $C$ control treatment. Means $+\mathrm{SE} ; N=9$

\section{Root morphology}

Root length was significantly affected by nematode infestation but the effect depended on the presence of earthworms. If earthworms were present, nematodes led to a root length increased on average by $24 \%\left(F_{[2,49]}=5.22, P=0.008\right.$ for the nematode $\times$ earthworm interaction; Fig. $1 b)$. In contrast, the presence of earthworms alone reduced root length compared to control plants. Similar results were obtained for root surface area (data not shown).

\section{Nitrogen concentration and $\mathrm{C} / \mathrm{N}$-ratios}

Nitrogen concentration in shoots varied between 1.2 and $1.5 \%$. It was significantly affected by nematode infestation but the effect depended on earthworms $\left(F_{[2,54]}=4.31\right.$, $P=0.018$ for the nematode $\times$ earthworm interaction). If earthworms were absent, $P$. penetrans, and in particular $M$. incognita, decreased shoot $\mathrm{N}$ concentration by 8 and $18 \%$, respectively; in the presence of earthworms this reduction disappeared (Fig. 2a).
Nitrogen concentration in roots varied between 1.4 and $1.9 \%$. It increased significantly in the presence of earthworms, on average by $18 \%\left(F_{[1,54]}=7.67, P=0.008\right)$, but remained unaffected by nematode infestation (Fig. 2b).

Earthworms $\left(F_{[1,54]}=4.91, P=0.03\right)$ but, in particular, nematodes $\left(F_{[2,54]}=42.68, P<0.0001\right)$ significantly affected the $\mathrm{C} / \mathrm{N}$ ratio in shoots. The $\mathrm{C} / \mathrm{N}$ ratio was strongly decreased in the presence of nematodes, on average by $27 \%$ (Fig. 2c). In contrast, earthworms generally increased shoot $\mathrm{C} / \mathrm{N}$ ratio by $7 \%$ thereby counteracting the effect of nematode infestation.

In contrast to shoots, root $\mathrm{C} / \mathrm{N}$ ratio was not affected by nematode infestation and decreased significantly in the presence of earthworms, on average by $22 \%\left(F_{[1,54]}=\right.$ 10.46, $P=0.002$; Fig. 2d).

\section{Glucosinolate concentration}

The major four glucosinolates in $S$. alba were identified as p-hydroxy-benzylglucosinolate (about $90 \%$ of total), benzylglucosinolate, 4-methoxy-indol-3-ylmethylglucosinolate and indol-3-ylmethylglucosinolate. Further, four minor aromatic and one minor aliphatic glucosinolates were detected but these were not identified further.

Earthworms significantly affected glucosinolate concentrations, with their impact differing significantly between the different glucosinolates but being unaffected by leaf age (Tables 1, 2). In young and old leaves they led to a significant increase of total (sum of all compounds, Fig. 3) and aromatic glucosinolate concentrations, on average by 43 and $44 \%$. In contrast, the concentration of the aliphatic glucosinolate was significantly reduced, on average by $68 \%$ (Table 2). Concentrations of indolic glucosinolates and benzylglucosinolate remained unaffected.

Nematode infestation significantly affected glucosinolate concentrations, with the impact differing between the different glucosinolates and depending on leaf age (Table 1). In young leaves, $P$. penetrans infestation significantly decreased total and aromatic glucosinolates by $63 \%$. This effect was even more distinct in old leaves, where $P$. penetrans infestation decreased concentrations of total and aromatic glucosinolates by 79 and $81 \%$, respectively (Fig. 4a). In the presence of earthworms, $P$. penetrans led to a decrease of total glucosinolate concentrations to nearly the same degree (Fig. 3). Further, due to P. penetrans infestation, benzylglucosinolate tended to decrease on average by $63 \%\left(F_{[2,54]}=2.98 ; P=0.06\right)$ but only young leaves were affected (Fig. 4c). In old leaves, the presence of $P$. penetrans significantly increased concentrations of the aliphatic glucosinolate, on average by $49 \%$ (Fig. 4b). Concentrations of indolic glucosinolates remained unaffected. Meloidogyne incognita infestation led to an increase of total and aromatic glucosinolate concentrations on average by 51 and $54 \%$, 

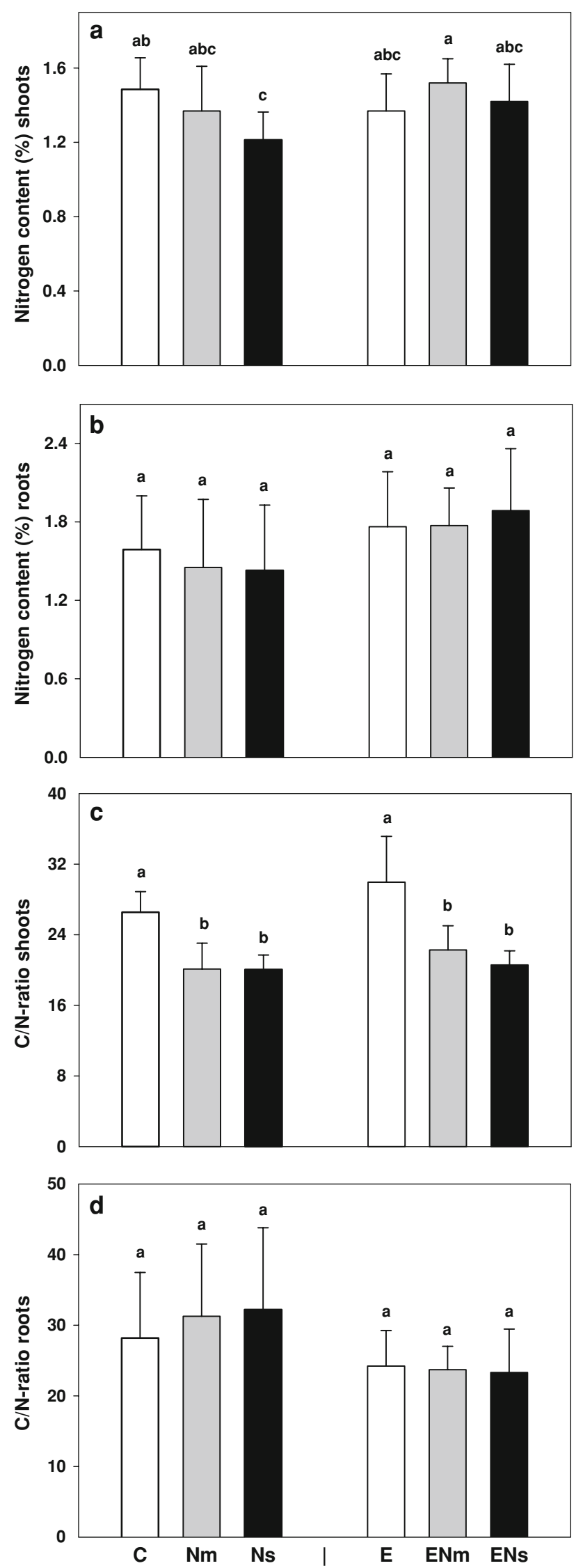

Fig. 2 Effects of earthworms (A. caliginosa; $E$ ) and nematode infestation $[P$. penetrans $(\mathrm{Nm})$ and $\mathrm{M}$. incognita $(\mathrm{Ns})]$ on (a) nitrogen content in shoots, (b) nitrogen content in roots, (c) $\mathrm{C} / \mathrm{N}$-ratio in shoots and (d) $\mathrm{C} / \mathrm{N}$-ratio in roots of $S$. alba. Significant differences are marked with different letters, $P<0.05$; Tukey's honestly significant difference (HSD); $C$ control treatment. Means $+\mathrm{SE} ; N=9$

Table 1 Repeated measures analysis of variance (rmANOVA)

\begin{tabular}{lrrc}
\hline Source & DF & $F$-value & $P$-value \\
\hline Between-subjects & & & \\
E & 1 & 4.05 & $0.0497^{*}$ \\
Nem & 2 & 11.62 & $<0.0001^{*}$ \\
E $\times$ Nem & 2 & 1.62 & 0.2076 \\
Within-subjects & & & \\
GS-group & 5 & 705.90 & $<0.0001^{*}$ \\
GS-group $\times$ E & 5 & 13.35 & $<0.0001^{*}$ \\
GS-group $\times$ Nem & 10 & 11.32 & $<0.0001^{*}$ \\
GS-group $\times$ E $\times$ Nem & 10 & 3.31 & $0.0125^{*}$ \\
Leaf age & 1 & 201.50 & $<0.0001^{*}$ \\
Leaf age $\times$ E & 1 & 1.86 & 0.1787 \\
Leaf age $\times$ Nem & 2 & 2.39 & 0.1022 \\
Leaf age $\times$ E $\times$ Nem & 2 & 1.53 & 0.2265 \\
GS-group $\times$ Leaf age & 5 & 81.72 & $<0.0001^{*}$ \\
GS-group $\times$ Leaf age $\times$ E & 5 & 2.74 & $0.0499^{*}$ \\
GS-group $\times$ Leaf age $\times$ Nem & 10 & 3.05 & $0.0096^{*}$ \\
GS-group $\times$ Leaf age $\times$ E $\times$ Nem & 10 & 1.42 & 0.2146 \\
\hline
\end{tabular}

$\overline{\text { Influence of Aporrectodea caliginosa (E) and Nematodes (Nem) Praty- }}$ lenchus penetrans and Meloidogyne incognita on glucosinolate concentration in leaves of Sinapis alba. Between-subjects-effects (Earthworms, Nematodes) and within-subjects-effects ( 1 repeated factor: glucosinolate-groups (GS-group), 2 repeated factor: leaf age) are listed, $N=9$

* $P<0.05$

respectively, but only if earthworms were also present (Fig. 3).

\section{Myrosinase activity}

Myrosinase activities were measured only in young leaves. Activity of soluble and insoluble myrosinases combined was not affected significantly by earthworms and nematode infestation. However, the presence of earthworms significantly decreased myrosinase activity by $39 \%$ when both fractions were added (total myrosinase activity; $F_{[1,30]}=$ $4.65 ; P=0.04$; Fig. 5).

\section{Discussion}

This study investigated the sole and interactive impacts of A. caliginosa, an endogeic earthworm species, and plant feeding nematodes, $P$. penetrans and $M$. incognita, on 
Table 2 General linear models (GLM) table of $F$-values and $P$-values on the effects of earthworms (E) and nematodes (Nem) on the glucosinolate concentrations in leaves of $S$. alba young leaves and old leaves, $N=9$

\begin{tabular}{|c|c|c|c|c|c|c|c|c|c|c|}
\hline \multirow[t]{2}{*}{ Treatment } & \multicolumn{2}{|c|}{ Total glucosinolates } & \multicolumn{2}{|c|}{ Aromatic glucosinolates } & \multicolumn{2}{|c|}{ Aliphatic glucosinolates } & \multicolumn{2}{|c|}{ Benzyl glucosinolates } & \multicolumn{2}{|c|}{ Indolic glucosinolates } \\
\hline & $F$ & $P$ & $F$ & $P$ & $F$ & $P$ & $F$ & $P$ & $F$ & $P$ \\
\hline \multicolumn{11}{|c|}{ Young leaves } \\
\hline $\mathrm{E}$ & 4.17 & $0.0500 *$ & 4.09 & $0.0487 *$ & 8.85 & $0.0045^{*}$ & 2.73 & 0.1047 & 1.12 & 0.2945 \\
\hline Nem & 11.15 & $0.0001 *$ & 11.09 & $0.0001 *$ & 0.50 & 0.6121 & 2.98 & 0.0599 & 0.36 & 0.6995 \\
\hline $\mathrm{E} \times \mathrm{Nem}$ & 1.85 & 0.1677 & 2.03 & 0.1427 & 1.04 & 0.3599 & 0.28 & 0.7594 & 0.37 & 0.6905 \\
\hline \multicolumn{11}{|l|}{ Old leaves } \\
\hline $\mathrm{E}$ & 6.86 & $0.0117 *$ & 7.98 & $0.0068 *$ & 16.51 & $0.0002 *$ & 1.38 & 0.2456 & 0.67 & 0.4172 \\
\hline Nem & 11.81 & $<0.0001 *$ & 13.36 & $<0.0001 *$ & 5.42 & $0.0075^{*}$ & 6.65 & $0.0028 *$ & 1.52 & 0.2299 \\
\hline $\mathrm{E} \times \mathrm{Nem}$ & 3.18 & $0.0501 *$ & 2.79 & 0.0712 & 0.35 & 0.7081 & 0.49 & 0.6174 & 0.08 & 0.9187 \\
\hline
\end{tabular}

$* P<0.05$

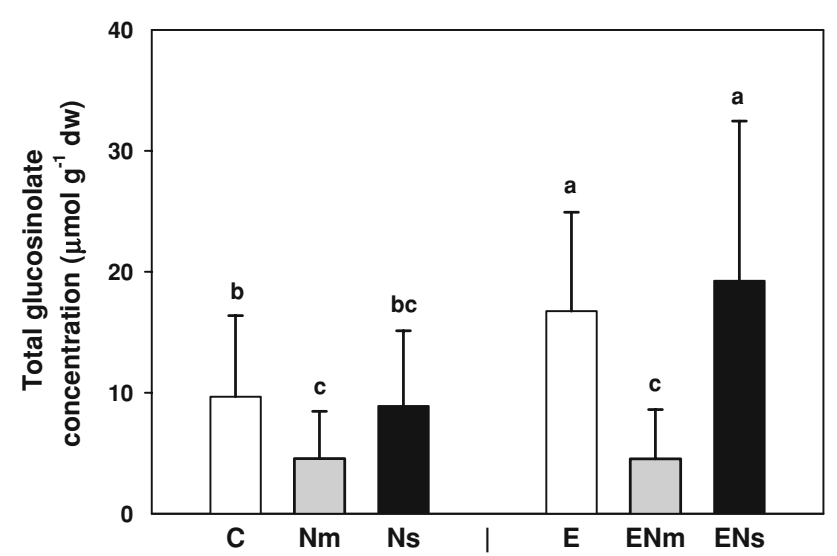

Fig. 3 Effects of earthworms (A. caliginosa, E) and nematode infestation [P. penetrans $(\mathrm{Nm})$ and $\mathrm{M}$. incognita $(\mathrm{Ns})]$ on concentrations of total glucosinolates in leaves of $S$. alba (averaged for young and old leaves); $C$ control treatment. Means $+\mathrm{SE} ; N=9$

growth and induction patterns in leaf tissue of the crucifer S. alba. We examined if, in addition to rhizophagous species, decomposer soil animals influence these traits aboveground. The results confirmed this assumption and revealed highly species-specific effects.

In contrast to our expectations, earthworms affected neither root nor shoot growth of the plants. Previous studies indicated that at least one of these parameters, often both, increase in presence of earthworms (Scheu 2001). The less pronounced effect of earthworms on plant morphology as compared to previous studies was likely due to the short duration of the experiment. As we were focussing on the chemical responses of plants, vigorously growing rather than mature plants were harvested. In contrast to earthworms, nematodes significantly decreased shoot biomass; nevertheless, total plant biomass remained unaffected. Wurst et al. (2006) documented a significant increase in shoot biomass of Brassica oleracea when nematodes were present. However, high infestation with parasitic nematodes often reduces the water and nutrient supply of the plant and interferes with plant development (Lambert and Bekal 2002), as was the case in the present study. As predicted, earthworms counteracted the detrimental effect of nematodes. Interestingly, root length was even increased in the combined treatment with earthworms and $P$. penetrans. Potentially, root damage by $P$. penetrans stimulated root regrowth and this was beneficially affected by increased nutrient availability in the presence of earthworms. In fact, the migratory feeding of $P$. penetrans and the high root infestation by this species likely resulted in more pronounced damage than by the sedentary and less abundant $M$. incognita. Increased biomass of A. caliginosa in the presence of $P$. penetrans also indicates that $P$. penetrans increased the availability of resources for earthworms, most likely in the form of dead and decaying roots.

Although earthworms did not affect plant biomass, they increased nitrogen concentration and the amount of nitrogen in roots, proving that they enhanced nitrogen availability to plants. Effects of nitrogen fertilisation on glucosinolates have been shown to vary in Brassicaceae, from no effects on glucosinolate concentration (Hwang et al. 2008) to substantial increases (Mert-Turk et al. 2008). However, the glucosinolate concentration of individual compounds is also finely tuned by the availability of other compounds like sulphur (Kopsell et al. 2007). Thus, nitrogen levels and nitrogen-based defence compounds do not necessarily correlate. Earthworms significantly affected glucosinolate concentrations in $S$. alba, confirming earlier findings with another Brassicaceae, Brassica oleracea, that earthworms can influence plant secondary metabolites aboveground (Wurst et al. 2006). In both studies, earthworms reduced aliphatic glucosinolates and increased concentrations of aromatic glucosinolates significantly. The results demonstrate that earthworms differentially affect glucosinolates and that these effects cannot simply be 

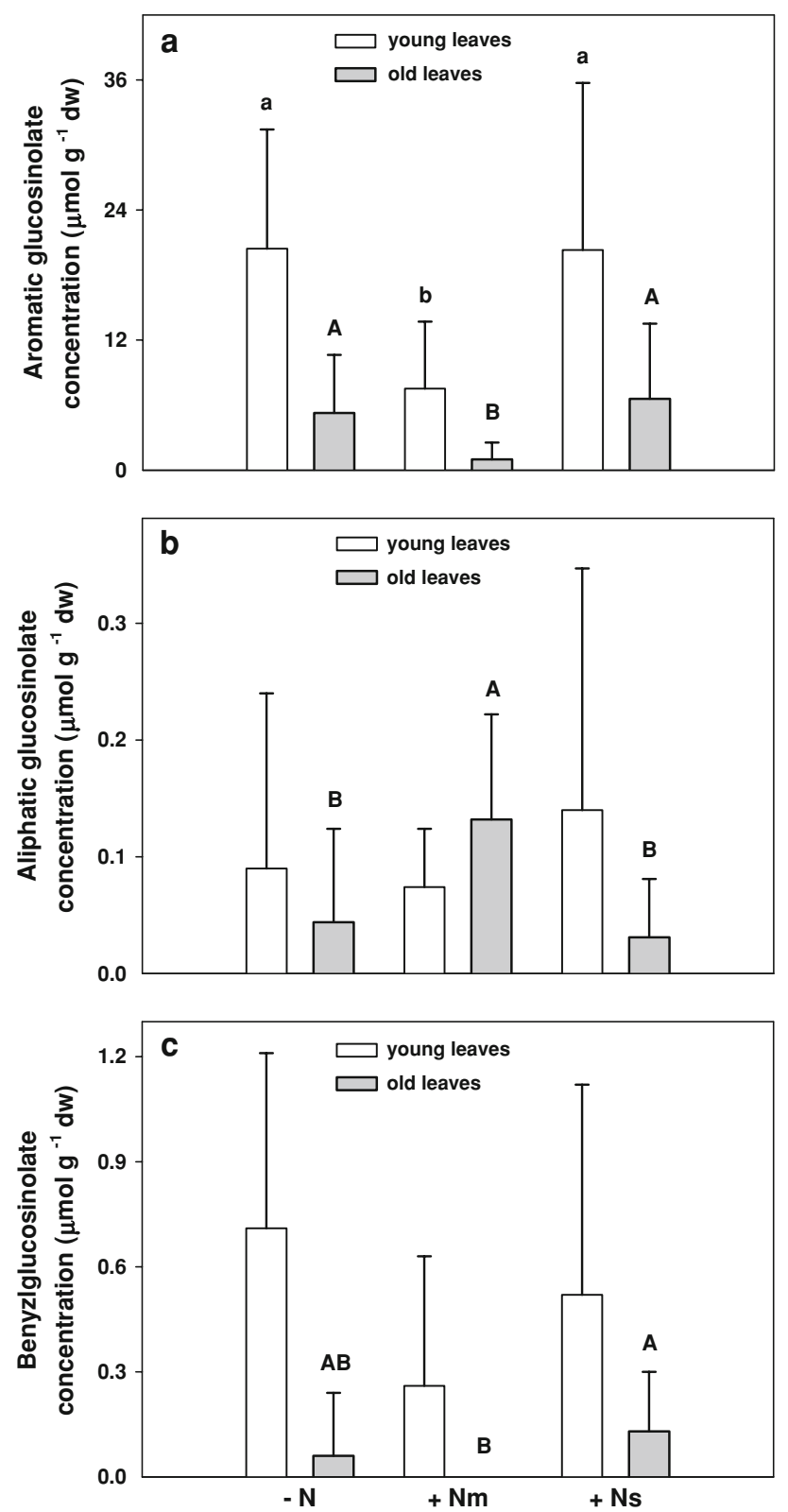

Fig. 4 Effects of nematode infestation $[P$. penetrans $(+\mathrm{Nm})$ and $M$. incognita (+Ns)] on concentrations of $\mathbf{a}$ aromatic glucosinolates, $\mathbf{b}$ aliphatic glucosinolates, and c benzylglucosinolate in young and old leaves of $S$. alba. Significant differences are marked with different letters, $P<0.05$; Tukey's honestly significant difference (HSD). Means $+\mathrm{SE} ; N=9$

explained just by increases in the amount of nitrogen needed for glucosinolate biosynthesis.

Nematodes also influenced the aboveground concentrations of glucosinolates in $S$. alba. Like earthworms, they affected the various glucosinolate classes differently. Further, the effect varied with nematode species. Concentrations of glucosinolates decreased specifically, when plants were infested with the migratory nematode $P$. penetrans, whereas the effect of the sedentary nematode $M$. incognita

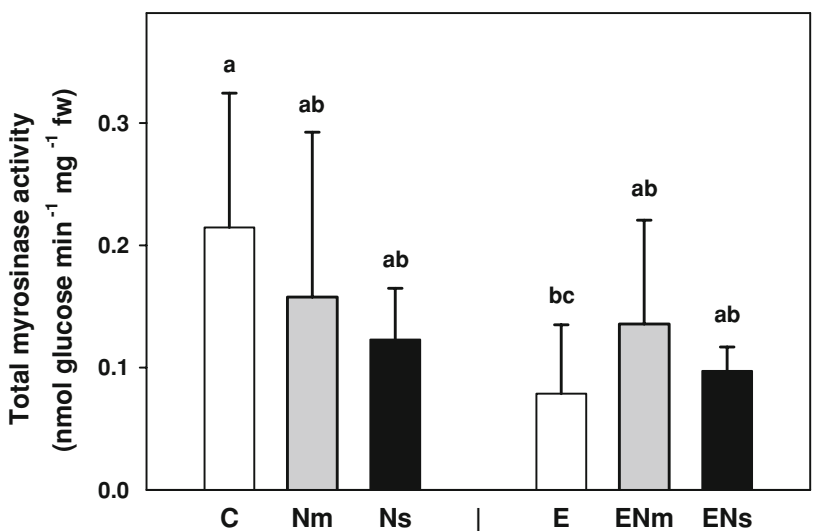

Fig. 5 Effects of earthworms (A. caliginosa, $E$ ) and nematode infestation $[P$. penetrans $(\mathrm{Nm})$ and $\mathrm{M}$. incognita $(\mathrm{Ns})]$ on total myrosinase activity (soluble and insoluble fractions combined) in young leaves of $S$. alba. Tukey's honestly significant difference (HSD); $P<0.05$. Means $+\mathrm{SE} ; N=5$

on the glucosinolate content was less pronounced. Similarly, a reduction of glucosinolate levels in shoots due to infestation with $P$. penetrans was also found in B. nigra (van Dam et al. 2005). In $S$. alba, induction by nematodes was more pronounced in young leaves, which have also constitutively much higher levels of glucosinolates. Interestingly, and conforming to our hypothesis, the effects of nematodes on glucosinolate concentrations were altered by earthworms. However, contrary to their effect on nematodemediated changes in plant growth, which was restricted to $P$. penetrans, earthworms modified the impact of M. incognita on total and aromatic glucosinolates. The results suggest that earthworms in general modulate plant defences, presumably by altering plant nutrition.

Indolic glucosinolates in leaves were the only measured trait that remained unaffected by both nematodes and earthworms. After aboveground herbivory by leaf chewers, indole glucosinolate concentrations increased in $S$. alba var. Salvo only locally (Martin and Müller 2007), but in the cultivar Silenda, 4-methoxy-indol-3-ylmethyl glucosinolate was also induced systemically in younger leaves (TraversMartin and Müller 2007). However, systemic signals might depend on the distance between the damaged and measured tissues, on the duration of challenge, as well as on the particular inducing species. It remains to be shown if earthworms and nematodes also impact on local concentrations of the various glucosinolates in root tissue.

The results of the myrosinase analyses were unexpected. Whereas the presence of earthworms led to an increase of the main glucosinolate compounds in S. alba, total myrosinase activity was reduced by almost $40 \%$ compared to the control plants. Nematode infestation had no influence on myrosinase activities in leaves. Martin and Müller (2007) reported that feeding by a specialist leaf herbivore increased both levels of glucosinolates and myrosinase 
activity. In contrast, feeding by a generalist herbivore led only to an increase in glucosinolates while myrosinase activities remaining unchanged (Travers-Martin and Müller 2007). These results demonstrate that responses of the substrate and the enzyme are largely uncoupled.

The ecological consequences of increased glucosinolate and myrosinase levels in aboveground tissue on herbivores can be rather diverse. Specialist and generalist herbivores have been shown to respond differently in their acceptance behaviour and performance, with generalists for example feeding less on high glucosinolate lines, whereas specialists were more affected by high myrosinase levels ( $\mathrm{Li}$ et al. 2000). Effects of earlier induction on subsequent herbivores are highly species-specific on all levels, the inducing organism, the plant species and the responding subsequent herbivore species. They range from negative effects on the performance of both specialist and generalists after previous herbivore induction (e.g. Poelman et al. 2008), to no effects on subsequent attackers (Travers-Martin and Müller 2007; Viswanathan et al. 2007) or even positive effects on specialists (Hopkins et al. 2009). More research is needed to disentangle the consequences of belowground induced responses in $S$. alba on the behaviour and performance of aboveground herbivore species.

Induction of plant defence compounds so far has been studied predominantly considering aboveground pathogens and herbivores as inducing agents. The results of this study support earlier findings (van Dam et al. 2005; Wurst et al. 2006) that by directly interacting with plants, root-feeding nematodes alter plant defence chemistry in the shoot, but the study also documents that the effect of nematodes varies with nematode species of different functional groups. Further, our results suggest that the effect of soil animals on plant defence is not restricted to root herbivores. Rather, secondary metabolite production as well as enzyme activities are also affected by decomposer animals in the rhizosphere, such as earthworms, thereby changing plant quality and nutrition. Interestingly, the two soil animal groups studied interacted and modulated the individual effects on plant defence. Modulation of nematode-mediated changes in plant defence likely was due to earthworms changing plant nutrition. The underlying mechanisms remain largely unknown but the results suggest a fine-tuned cross-talk between different signaling pathways. Overall, the results indicate that if we are to understand modifications of aboveground processes by belowground biota, interactions of rhizosphere biota and their feedbacks to plants, decomposers need much closer attention.

Acknowledgement Financial support for the work on glucosinolate and myrosinase analyses was received from the Sonderforschungsbereich 567 'interspecific interactions' of the Deutsche Forschungsgemeinschaft.

\section{References}

Albers D, Schaefer M, Scheu S (2006) Incorporation of plant carbon into the soil animal food web of an arable system. Ecology $87: 235-245$

Bartlet E, Kiddle G, Williams I, Wallsgrove R (1999) Wound-induced increases in the glucosinolate content of oilseed rape and their effect on subsequent herbivory by a crucifer specialist. Entomol Exp Appl 91:163-167

Baylis JP, Cherrett JM, Ford JB (1986) A survey of the invertebrates feeding on living clover roots (Trifolium repens $\mathrm{L}$.) using $32-\mathrm{P}$ as a radiotracer. Pedobiologia 29:201-208

Bezemer MT, van Dam NM (2005) Linking aboveground and belowground interactions via induced plant defenses. Trends Ecol Evol 20:617-624

Bezemer TM, Wagenaar R, van Dam NM, Wäckers FL (2003) Interactions between above- and belowground insect herbivores as mediated by the plant defense system. Oikos 101:555-562

Blouin M, Zuily-Fodil Y, Pham-Ti AT, Laffray D, Reversat G, Pando A, Tondoh J, Lavelle P (2005) Belowground organism activities affect plant aboveground phenotype, inducing plant tolerance to parasites. Ecol Lett 8:202-208

Bruckner A, Wright J, Kampichler C, Bauer R, Kandeler E (1995) A method of preparing mesocosms for assessing complex biotic processes in soil. Biol Fertil Soils 19:257-262

Cipollini D, Purrington CB, Bergelson J (2003) Costs of induced responses in plants. Basic Appl Ecol 4:79-85

Halkier B, Gershenzon J (2006) Biology and biochemistry of glucosinolates. Annu Rev Plant Biol 57:303-333

Hopkins RJ, van Dam NM, van Loon JJA (2009) Role of glucosinolates in insect-plant relationships and multitrophic interactions. Annu Rev Entomol 54:57-83

Hwang SY, Liu CH, Shen TC (2008) Effects of plant nutrient availability and host plant species on the performance of two Pieris butterflies (Lepidoptera: Pieridae). Biochem Syst Ecol 36:505-513

Hyodo F, Tayasu I, Konate S, Tondoh JE, Lavelle P, Wada E (2008) Gradual enrichment of $15-\mathrm{N}$ with humification of diets in a below-ground food web: relationship between $15-\mathrm{N}$ and diet age determined using 14-C. Funct Ecol 22:516-522

Ilieva-Makulec K, Makulek G (2002) Effect of the earthworm Lumbricus rubellus on the nematode community in a peat meadow soil. Eur J Soil Biol 38(1):59-62

Karban R, Baldwin IT (1997) Induced responses to herbivory. Chicago University Press, Chicago

Kopsell DA, Barickman TC, Sams CE, McElroy JS (2007) Influence of nitrogen and sulfur on biomass production and carotenoid and glucosinolate concentrations in watercress (Nasturtium officinale R Br). J Agric Food Chem 55:10628-10634

Lambert K, Bekal S (2002) Introduction to plant parasitic-nematodes. The plant health instructor. Department of Crop Sciences, University of Illinois, IL

Li Q, Eigenbrode SD, Stringam GR, Thiagarajah MR (2000) Feeding and growth of Plutella xylostella and Spodoptera eridania on Brassica juncea with varying glucosinolate concentrations and myrosinase activities. J Chem Ecol 26:2401-2419

Martin N, Müller C (2007) Induction of plant responses by a sequestering insect: relationship of glucosinolate concentration and myrosinase activity. Basic Appl Ecol 8:13-25

Matyssek R, Agerer R, Ernst D, Munch JC, Osswald W, Pretzsch H, Priesack E, Schnyder H, Treutter D (2005) The plant's capacity an regulating resource demand. Plant Biol 7:560-580

Mert-Turk K, Gul MK, Egesel CO (2008) Nitrogen and fungicide applications against Erysiphe cruciferarum affect quality components of oilseed rape. Mycopathologia 165:27-35 
Müller C, Sieling N (2006) Effects of glucosinolate and myrosinase levels in Brassica juncea on a glucosinolate-sequestering herbivore-and vice versa. Chemoecology 16:191-201

Müller C, Wittstock U (2005) Uptake and turn-over of glucosinolates sequestered in the sawfly Athalia rosae. Insect Biochem Mol Biol 35:1189-1198

Poelman EH, Broekgaarden C, van Loon JJA, Dicke M (2008) Inducing herbivore affects direct defense response against subsequent colonist: contrasting consequences for species abundance in the field. Mol Ecol 17:3352-3365

Pontoppidan B, Hopkins R, Rask L, Meijer J (2005) Differential wound induction of the myrosinase system in oilseed rape (Brassica napus): contrasting insect damage with mechanical damage. Plant Sci 168:715-722

Poveda K, Steffan-Dewenter I, Scheu S, Tscharntke T (2005) Effects of decomposers and herbivores on plant performance and aboveground plant-insect interactions. Oikos 108:503-510

Preisser EL, Strong DR (2004) Climate affects predator control of an herbivore outbreak. Am Nat 163:754-762

Scheu S (2001) Plants and generalist predators as links between the below-ground and above-ground system. Basic Appl Ecol 2:3-13

Scheu S, Theenhaus A, Jones TH (1999) Links between the detritivore and the herbivore system: effects of earthworms and Collembola on plant growth and aphid development. Oecologia 119:541-551

Scheu S, Ruess L, Bonkowski M (2005) Interactions between microorganisms and soil micro- and mesofauna. In: Buscot F, Varma A (eds) Microorganisms in soils: roles in genesis and functions, soil biology, vol 3. Springer, Berlin, pp 253-275

Travers-Martin N, Müller C (2007) Specificity of induction responses in a Brassicaceae and their effects on a specialist herbivore. J Chem Ecol 33:1582-1597

Travers-Martin N, Müller C (2008) Specificity of induction responses in Sinapis alba L.: plant growth and development. Plant Signal Behav 3:311-313
Travers-Martin N, Kuhlmann F, Müller C (2008) Revised determination of free and complexed myrosinase activities in plant extracts. Plant Physiol Biochem 46:506-516

van Dam NM, Raaijmakers CE, van der Putten WH (2005) Root herbivory reduces growth and survival of the shoot feeding specialist Pieris rapae on Brassica nigra. Entomol Exp Appl 115:161-170

van der Putten WH, Vet LEM, Harvey JA, Wäckers FL (2001) Linking above- and belowground multitrophic interactions of plants, herbivores, pathogens, and their antagonists. Trends Ecol Evol 16:547-554

Viswanathan DV, Lifchits OA, Thaler JS (2007) Consequences of sequential attack for resistance to herbivores when plants have specific induced responses. Oikos 116:1389-1399

Waghorn TS, Leathwick DM, Chen LY, Gray RAJ, Skipp RA (2002) Influence of nematophagous fungi, earthworms and dung burial on development of the free-living stages of Ostertagia (Teladorsagia) circumcincta in New Zealand. Vet Parasitol 104:119-129

Wittstock U, Kliebenstein DJ, Lambrix V, Reichelt M, Gershenzon J (2003) Glucosinolate hydrolysis and its impact on generalist and specialist insect herbivores. In: Romeo JT (ed) Recent advances in phytochemistry, vol 37. Pergamon, Amsterdam, pp 101-125

Wurst S, Jones TH (2003) Indirect effects of earthworms (Aporrectodea caliginosa) on an above-ground tritrophic interaction. Pedobiologia 47:91-97

Wurst S, Dugass-Gobena D, Scheu S (2004) Earthworms and litter distribution affect plant-defensive chemistry. J Chem Ecol 30:691-701

Wurst S, Langel R, Rodger S, Scheu S (2006) Effects of belowground biota on primary and secondary metabolites in Brassica oleracea. Chemoecology 16:69-73

Yeates GW (1981) Soil nematode populations depressed in the presence of earthworms. Pedobiologia 22:191-195

Zangerl AR (2003) Evolution of induced plant responses to herbivores. Basic Appl Ecol 4:91-103 